\title{
Arrays of Copper Microelectrodes from Disposable Chips: Fabrication and Characterization
}

\author{
Giane S. Higino, ${ }^{\circledR a}$ Ítalo R. Machado, ${ }^{b}$ Gabriel F. Nascimento ${ }^{c}$ and Jairo J. Pedrotti ${ }^{\circledR}, c$ \\ ${ }^{a}$ Centro de Pesquisas Avançadas em Grafeno e Nanomateriais, MackGraphe, \\ 01302-907 São Paulo-SP, Brazil \\ ${ }^{b}$ Instituto de Química, Universidade de São Paulo, 05513-907 São Paulo-SP, Brazil \\ ${ }^{c}$ Escola de Engenharia, Universidade Presbiteriana Mackenzie, 01302-907 São Paulo-SP, Brazil
}

\begin{abstract}
A simple, fast, and low-cost process to fabricate arrays of copper microelectrodes (CuMEs) based on disposable electronic microchips is described. Arrays with 8 to $20 \mathrm{CuMEs}$ were characterized by energy-dispersive X-ray spectroscopy and cyclic voltammetry techniques. The closest interelectrode distance in the arrays is $358 \pm 22 \mu \mathrm{m}$, and the minor radius ranged from 10.6 to $13.5 \mu \mathrm{m}$. The microchips with CuMEs were sealed in epoxy resin to fabricate the rod and flat-shaped platforms, allowing the CuMEs to be addressed separately. Glucose, hydrazine, and nitrate were used as analyte models for voltammetric and amperometric detection at CuMEs arrays, showing excellent performance in batch and flow-through cells. Glucose measurements carried out with flow injection analysis system with amperometric detection at an array of $20 \mathrm{CuMEs}$ showed a wide linear range $\left(0.020-4.0 \mathrm{mmol} \mathrm{L}^{-1}\right)$, high sensitivity $\left(734.1 \mu \mathrm{A} \mathrm{L} \mathrm{mmol}{ }^{-1} \mathrm{~cm}^{-2}\right)$, and

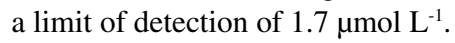

Keywords: copper microelectrode arrays, glucose, nitrate, electrochemical detection, flow analysis

\section{Introduction}

Copper electrodes have attractive use as electrochemical due to their low cost, good mechanical stability, high electrical conductivity, and easy use in microfabrication processes. ${ }^{1,2}$ Additionally, depending on solution composition, the copper surface can also be quickly renewed by electrochemical treatment during the measurements steps to minimize its passivation due to its side-reactions with the sample or electrolyte components. ${ }^{3,4}$ Macro and micro-copper electrodes of different shapes have been investigated for applications in environmental, industrial, clinical, and pharmaceutical fields. ${ }^{5-9}$ On the other hand, the use of microelectrodes offers significant advantages over large-size electrodes, including the radial diffusion dominance, which yields a sigmoid voltammetric curve, and a reduced capacitive charging current that allows improving the sensitivity of electroanalytical sensors. They can also provide fast cell-response time and negligible ohmic potential drop (iR drop) in the electrochemical cell, facilitating the operation by a simple two-electrode system.

*e-mail: jpedrotti@ mackenzie.br
Further, the electrodes with ultrasmall dimensions are compatible with monitoring chemical species in microenvironments, stimulating applications in different science fields. ${ }^{10-13}$ However, one disadvantage associated with ultramicroelectrode is the low faradaic current signal (usually at $\mathrm{nA}$ or $\mathrm{pA}$ levels) generated during the electrochemical process when a single sensor is used. In order to mitigate this drawback, the use of microelectrode arrays is recommended since each microelectrode working in parallel can individually contribute to the total measured current. Microelectrodes arrays can also assure the detector response even when some microelectrode is not active, which does not happen when only a single microelectrode is used.

Different techniques have been used to prepare copper microelectrodes arrays, including photolithography, electrodeposition, and $\mathrm{Cu}$ flat flexible cables. ${ }^{2,14-16}$ Among these techniques, the photolithography processes are more common. They allow the fabrication of a large number of microelectrodes easily controlled and highly reproducible in size. However, these processes usually demand cleanroom, high-cost instrumentation, and highly qualified operators. 
In this work, a low-cost and straightforward process to fabricate platforms of copper microelectrodes arrays with 8 to 20 units obtained from microchips is described. The new microsensor arrays were characterized by energy-dispersive $\mathrm{X}$-ray spectroscopy and cyclic voltammetry techniques. The copper microelectrodes (CuMEs) platforms were evaluated for glucose, hydrazine, and nitrate electrochemical measurements in batch and flow-through cells, showing excellent performance.

\section{Experimental}

\section{Reagents and solutions}

All reagents were analytically graded and were used without further purification. The stock solutions and subsequent dilutions were prepared by using deionized water with a resistivity of $18.2 \mathrm{M} \Omega \mathrm{cm}$ obtained from the Smart Park Millipore (Merck, Darmstadt, Germany) purification system. The analytical solutions were prepared daily just before their use. The epoxy resin and the catalyst used for polymer curing were purchased at Redelease Co. (São Paulo, Brazil).

\section{Preparation of CuMEs platforms}

The copper microelectrodes were prepared from surface mounted device (SMD) disposable microchips provided with 8 to 20 pins, which use copper microwires to connect the active part of the integrated circuit to the external terminals of a semiconductor. The code and the manufacturer of the SMD components often used to fabricate the CuMEs are in Supplementary Information (SI) section.

The copper microdisks manufacture starts with the upper polymeric part of the chip removal with a help of a sandpaper of 800 mesh, which is followed until the complete disruption of the copper wires bonding, according to the procedure previously described. ${ }^{17}$ Afterward, the copper disks are carefully polished with sandpapers ranging from 1,000 to 3,000 mesh until they reach disks with a well-defined elliptical shape. This step is followed by visual inspections in an optical microscope at the end of each stage. In the last step, the $\mathrm{Cu}$ microdisks are polished with alumina with 0.50 and $0.03 \mu \mathrm{m}$ granulometry, followed by a short cleanness step by rinsing with deionized water. The chip is transferred to a beaker with deionized water at the next step, and it was sonicated for $10 \mathrm{~min}$. This cleaning process was repeated at least five times for residues removal remained after the polishing process. Figure 1a shows a typical SMD microchip used to fabricate the CuMEs, the distribution of the CuMEs on the array (Figure 1b), and the usual shape of a random CuME (Figure 1c).
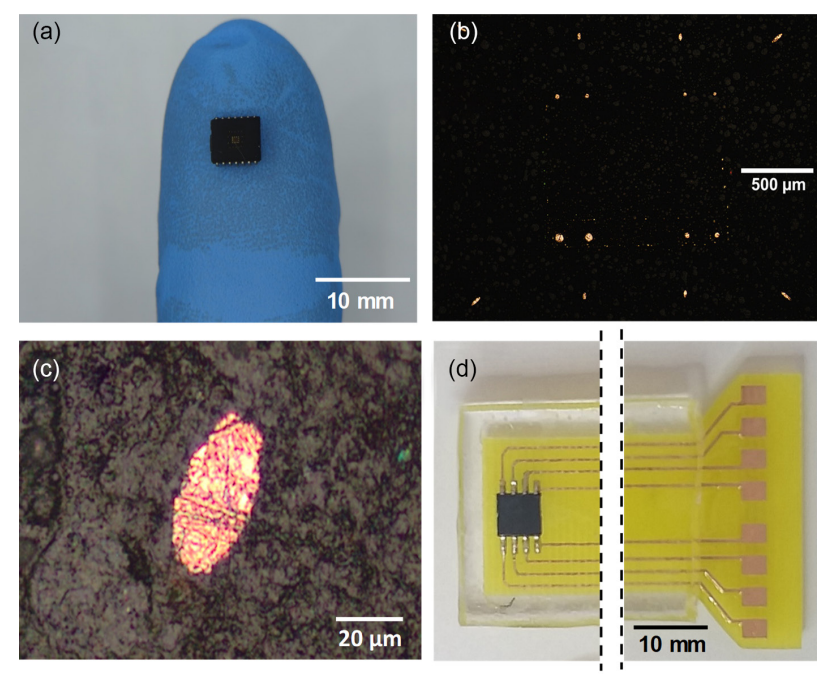

Figure 1. Image of a microchip with 14 pins (a); optical image of an array of eight microelectrodes (b); one single and random copper microelectrode (c); flat platform (d).

The chip with $\mathrm{Cu}$ microdisks was then fixed with $\mathrm{Pb}-\mathrm{Sn}$ solder on a printed circuit board $(20 \times 50 \mathrm{~mm})$ to ensure an independent electrical contact with each microdisk. Next, the chip was pressed on a double-faced adhesive tape, previously glued on a $10 \times 10 \mathrm{~mm}$ glass plate. Afterward, a polyethylene mold ( $40 \mathrm{~mm}$ long $\times 2 \mathrm{~mm}$ high $\times 25 \mathrm{~mm}$ wide) was placed on the adhesive tape. The glass surface was then vertically positioned on the bench with the help of a clamp connected to a lab support stand to fill the mold with epoxy resin. The flat platform obtained after the resin curing process for around $6 \mathrm{~h}$ is depicted in Figure 1d.

Thin wires were welded, for platform fabrication in rod-shaped, at the external terminals of the microchip to make the individual electric contact with the copper disks.

Afterward, the polished chip was positioned at the tip of a high-density polyethylene tube (inner diameter (i.d.) $=10 \mathrm{~mm}$ ), carefully filled with epoxy resin serving as the mold.

Before its use, the CuMEs have rinsed with acetone for removing any glue residues from the adhesive tape used to fix the chip inside the mold. In routine use, the surface of the microelectrodes was cleaned with alumina mechanical polishing. However, after some days without using the copper electrodes, sometimes was observed a dark layer covering partially or totally their surface, suggesting the copper oxide formation. So, in this condition, just alumina mechanical polishing was not enough to properly cleaning the electrodes. As for this condition, we used a $0.10 \mathrm{~mol} \mathrm{~L}^{-1}$ $\mathrm{HCl}$ solution drop in contact with the microdisks for a short period, no more than $60 \mathrm{~s}$, followed by a rinse with 
deionized (DI) water. The visual effect of this chemical treatment can be seen in Figure S1, SI section.

\section{Flow cell design}

The flow cell consists of two acrylic blocks ( $40 \mathrm{~mm}$ wide, $10 \mathrm{~mm}$ high, and $40 \mathrm{~mm}$ long) affixed by four brass screws. A schematic diagram of the flow cell built in the laboratory is depicted in Figure 2. A central hole $(8.0 \times 5.0 \mathrm{~mm})$ was made in the upper block (Figure $2 b$ ) with an internal volume of $1.0 \mathrm{~mL}$, to insert the three electrodes, the inlet, and the outlet solution. A polyetheretherketone (PEEK) tubing $30 \mathrm{~mm}$ long (i.d. $=0.3 \mathrm{~mm}$ ) was used to conduct the solution onto the CuMEs array working electrode. The $\mathrm{Ag} / \mathrm{AgCl}$ reference electrode $\left(3.0 \mathrm{~mol} \mathrm{~L}^{-1} \mathrm{KCl}\right){ }^{18}$ was positioned beside the PEEK tubing. A stainless-steel tubing (i.d. $=1.5 \mathrm{~mm}$ ) was utilized as the auxiliary electrode and outlet solution. The O-ring of Viton ${ }^{\circledR}$ inserted between the two acrylic blocks helped to adapt the working electrode in the electrochemical cell, avoiding electrolyte leakage.



Figure 2. Schematic diagram of the wall-jet flow-through cell; (a) and (b) acrylic blocks; (c) $\mathrm{Ag} / \mathrm{AgCl}$ reference electrode; (d) inlet solution; (e) auxiliary electrode and outlet solution; (f) CuMEs working electrode. In detail, a platform with an array of CuMEs working electrode.

Instrumentation

The CuMEs fabrication was followed by visual inspection by using a microscope Olympus model X51M (Nagano, Japan) provided with magnification lenses from 10 to 100 times. The energy X-ray dispersive spectroscopy (EDS) analyses were performed with a scanning electron microscopy JEOL, model JSM-7800F (Tokyo, Japan), by using an acceleration voltage of $10 \mathrm{KeV}$. The electrochemical measurements were carried out by using a $\mu$ Autolab potentiostat computer-controlled by NOVA V.1.1 (Herisau, Switzerland) software combined with a lab-made Faraday cage to protect the electrochemical cell from the interference of environmental noise. The cyclic voltammetry measurements were performed with a conventional electrochemical cell ( $10 \mathrm{~mL}$ internal volume) using CuMEs as a working electrode, an $\mathrm{Ag} / \mathrm{AgCl}$ reference electrode, and a Pt wire as the auxiliary electrode. The flow cell described in "Flow cell design" sub-section was used for glucose amperometric detection in the flow injection system. The solutions were propelled with an Ismatec peristaltic pump, MS-REGLO model (Glattbrugg, Switzerland). Samples and analytical solutions were injected into the flow injection analysis (FIA) system with a homemade, manually operated rotatory valve provided with a $100 \mu \mathrm{L}$ loop volume. All measurements were performed at $22 \pm 1.0^{\circ} \mathrm{C}$ temperature.

\section{Results and Discussion}

The CuMEs fabrication process is simple, cheap, and requires neither special tools nor a highly skilled operator. The $\mathrm{Cu}$ microelectrodes are usually ellipse-shaped (Figure 1c) and arranged in an almost circular pattern on the chip surface. The CuMEs show a minor radius of 12.4; 10.6 and $13.5 \mu \mathrm{m}$ in arrays of 8,14 , and 20 microelectrodes, respectively, and the mean center-to-center distance between the two closest electrodes higher than $370 \mu \mathrm{m}$, which is more than 27 times higher than the radius in the most density packaged array. This information suggests little or no overlap of diffusion layers between the electrodes in the array. At this condition, the measured current signal is amplified by the number of active electrodes contained in the array. ${ }^{19}$ Table $\mathrm{S} 1$ (SI section) shows additional geometric information of the proposed CuMEs arrays. Figure S2 (SI section) shows the contribution of each $\mathrm{Cu}$ microelectrode in an array with eight microelectrodes. As can be seen, the sum of the limiting current of each electrode represents more than $99 \%$ of the limiting current of the array (Figure S2f), evidencing the advantage of using the CuMEs array for electroanalytical applications.

\section{Characterization of microelectrodes}

Energy-dispersive X-ray measurements were performed to evaluate the chemical composition of the microdisks. A typical EDS spectrum of a microdisk sample obtained from an array containing 20 units is shown in Figure 3a. The elemental composition consisted mainly of $\mathrm{Cu}$ and small amounts of carbon and aluminum in the samples. According to the EDS results, the atomic proportions are $93.7 \%$ copper, $5.5 \%$ carbon, and $0.8 \%$ aluminum. The voltammetric profile of a CuMEs array with eight units in a $0.50 \mathrm{~mol} \mathrm{~L}^{-1} \mathrm{NaOH}$ solution was examined in the potential window of -1.5 to $0.80 \mathrm{~V} v s . \mathrm{Ag} / \mathrm{AgCl}$ at a scan rate of $25 \mathrm{mV} \mathrm{s}^{-1}$. The peak signals in Figure $3 \mathrm{~b}$ can be attributed to various oxidation states of copper in alkaline solution, according to previous studies ${ }^{20-22}$ carried 
out with metallic copper electrodes in alkaline solution. The first anodic current peak at $-0.39 \mathrm{~V}\left(\mathrm{~A}_{\mathrm{I}}\right)$ corresponds to the oxidation of metallic copper to its first oxidation state, $\mathrm{Cu}$. The second anodic signal peak at $-0.07 \mathrm{~V}\left(\mathrm{~A}_{\text {II }}\right)$ is assigned to $\mathrm{Cu}^{\mathrm{II}}$ formation, resulting of oxidative processes of $\mathrm{Cu}^{0} / \mathrm{Cu}^{\mathrm{II}}$ and $\mathrm{Cu} / \mathrm{Cu}^{\mathrm{II}} \cdot{ }^{20,21}$ The different electrochemical processes between 0.40 and $0.80 \mathrm{~V}$ lead to peak distortion, as the shoulder is close to $0.18 \mathrm{~V}^{21,22}$ The third and discrete peak anodic observed at $0.52 \mathrm{~V}\left(\mathrm{~A}_{\text {III }}\right)$ is frequently described by the presence of $\mathrm{Cu}^{\mathrm{III}}$ that appears in the form of $\mathrm{CuOOH}$ or $\mathrm{Cu}(\mathrm{OH})_{4}{ }^{-22-25}$ The species of $\mathrm{Cu}^{\mathrm{III}}$ are unstable and highly oxidizing, being attractive to some electrocatalytic oxidation processes, particularly for analytical applications. ${ }^{26-28}$

At the reverse scan rate, the I-E curve presents two characteristic cathodic peaks at -0.56 and $-0.92 \mathrm{~V}$, corresponding to the regeneration of $\mathrm{Cu}^{\mathrm{I}}$ and $\mathrm{Cu}^{0}$, respectively. ${ }^{22,29,30}$ Thus, in general, our finds with the proposed CuMEs suitably fit the previous studies ${ }^{20-25,29,30}$ carried out with copper electrodes in alkaline solutions.

\section{Analytical performance}

To evaluate the analytical performance of the CuMEs, we used glucose and hydrazine as the analyte models for preliminary voltammetric measurements. Figure 4A shows the typical voltammetric response for glucose at 2.0 to $9.5 \mathrm{mmol} \mathrm{L}^{-1}$ concentration range at eight $\mathrm{CuMEs}$ in $0.10 \mathrm{~mol} \mathrm{~L}^{-1} \mathrm{NaOH}$ solution by sweeping the potential between -0.20 to $+0.65 \mathrm{~V}$ at a scan rate of $20 \mathrm{mV} \mathrm{s}^{-1}$. At the electrolyte solution, the $\mathrm{CV}$ showed a low residual current at window potential from -0.20 to $+0.65 \mathrm{~V}$. At solutions containing glucose, the anodic current signals presented well-defined sigmoidal waves, indicating that the spherical diffusion corresponded to the analyte dominance process toward the CuOMEs surface.

The voltammetric CuOMEs response for hydrazine at

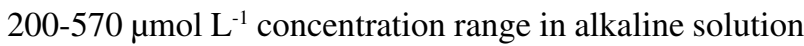
is depicted in Figure 4B. The well-defined voltammetric waves confirm the excellent performance of the CuOMEs for $\mathrm{N}_{2} \mathrm{H}_{4}$ sensing.

The anodic current from $\mathrm{N}_{2} \mathrm{H}_{4}$ oxidation to $\mathrm{N}_{2}$ started at $+0.023 \mathrm{~V}$ and reached the limiting-current region at around $+0.40 \mathrm{~V}$, and extended up to $+0.60 \mathrm{~V}$. The anodic steady-state current signals rose linearly with the increasing concentrations for both electroactive species, as it can be seen in the insets, and obeyed the following equations: $\mathrm{I}(\mathrm{nA})=-3.96+49.6 \times \mathrm{C}_{\text {glucose }}, \mathrm{mmol} \mathrm{L}^{-1}$ and $\mathrm{I}(\mathrm{nA})=-0.406+86.5 \times \mathrm{C}_{\text {hydrazine }}, \mu \mathrm{mmol} \mathrm{L} \mathrm{m}^{-1}$.

Nitrate has a great interest in the environmental field,


Figure 3. Energy dispersive X-ray elemental analysis of a CuME (a) and a typical cyclic voltammogram obtained with eight $\mathrm{CuMEs}$ in $0.5 \mathrm{~mol} \mathrm{~L}^{-1} \mathrm{NaOH}$ at $25 \mathrm{mV} \mathrm{s}^{-1}$ scan rate (b).
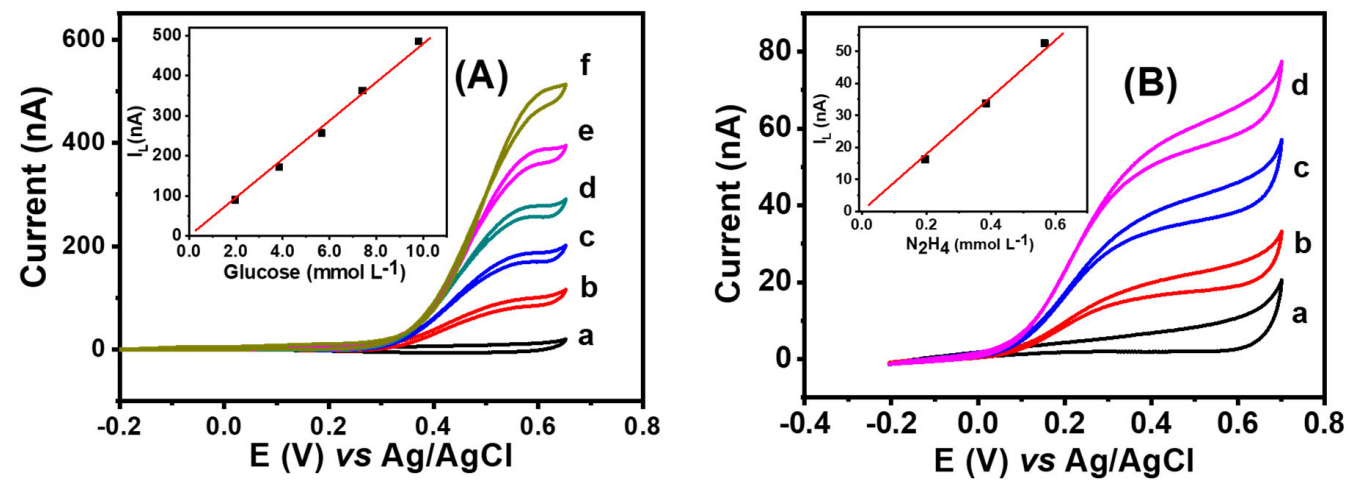

Figure 4. Voltammetric glucose response (A) and $\mathrm{N}_{2} \mathrm{H}_{4}$ (B) on an array of CuMEs in 0.10 mol L-1 $\mathrm{NaOH}$. Glucose concentration: (a) 0.0; (b) 2.0; (c) 3.8; (d) 5.7; (e) 7.4; (f) $9.5 \mathrm{mmol} \mathrm{L}^{-1}$. $\mathrm{N}_{2} \mathrm{H}_{4}$ concentration: (a) 0.0; (b) 200; (c) 390; (d) $570 \mu \mathrm{mol} \mathrm{L}-1$. Scan rate: $20 \mathrm{mV} \mathrm{s}^{-1}$. 
and it is electroactive at copper electrode surfaces in acidic media through a reduction step involving an eightelectron transfer (equation 1). Depending on the supporting electrolyte composition, this step can occur from -0.45 to $-0.70 \mathrm{~V}$ versus saturated calomel electrode (SCE). ${ }^{31}$

$\mathrm{NO}_{3}{ }^{-}+8 \mathrm{e}^{-}+10 \mathrm{H}^{+} \rightleftarrows \mathrm{NH}_{4}^{+}+3 \mathrm{H}_{2} \mathrm{O}$

We used a platform with twenty CuMEs to evaluate the square wave voltammetry response for nitrate

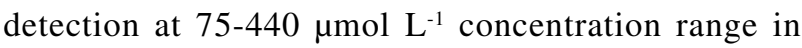
$0.10 \mathrm{~mol} \mathrm{~L}^{-1} \mathrm{Na}_{2} \mathrm{SO}_{4}+0.050 \mathrm{~mol} \mathrm{~L}^{-1} \mathrm{KCl}$ electrolyte solution at $\mathrm{pH}$ 2.0. The square wave voltammograms obtained showed well-shaped cathodic peaks resulting from nitrate reduction that started at $-0.39 \mathrm{~V}$ and attained a maximum at $-0.53 \mathrm{~V}$, as shown in Figure 5. An analysis of the current peak signals versus nitrate concentration (inset) by linear regression showed an $\mathrm{R}$-square $=0.998$ and obeyed the equation: $\mathrm{I}(\mathrm{nA})=-1.94-0.22 \times \mathrm{C}_{\text {nitrate }}$. At this condition, the limit of detection $(3 \times$ standard deviation of the blank


limit of quantification at $53.3 \mu \mathrm{mol} \mathrm{L}{ }^{-1}$, suggesting that the

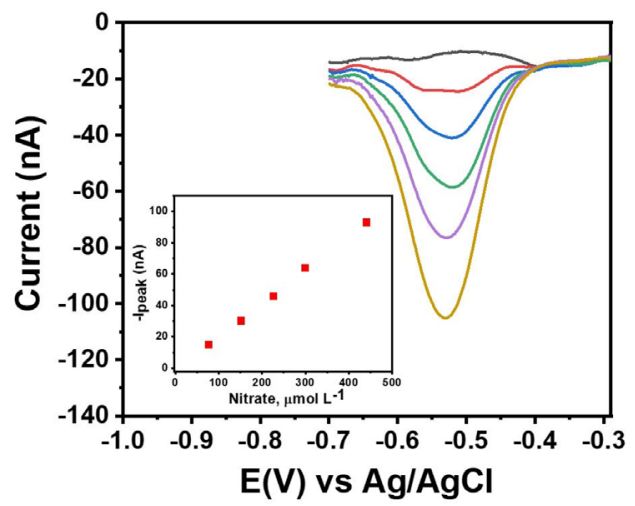

Figure 5. Square wave voltammograms of nitrate at an array of twenty CuMEs in $0.10 \mathrm{~mol} \mathrm{~L}^{-1} \mathrm{Na}_{2} \mathrm{SO}_{4}$ and $0.050 \mathrm{~mol} \mathrm{~L}^{-1} \mathrm{KCl}, \mathrm{pH}=2.0$. The inset shows the resulting calibration plot. Frequency: $20 \mathrm{~Hz}$; pulse amplitude: $10 \mathrm{mV}$ and step potential: $2 \mathrm{mV}$.

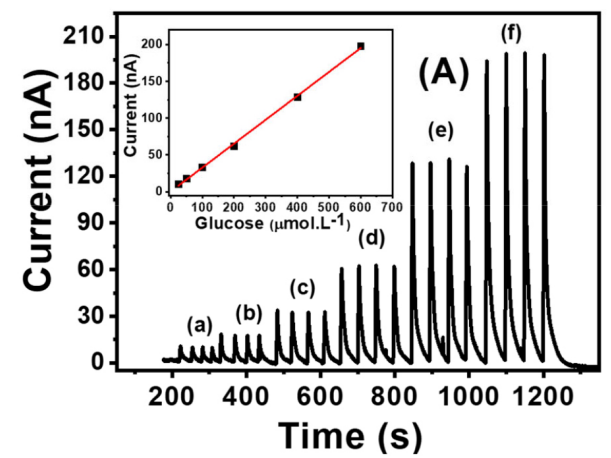

proposed CuMEs platforms can be a good analytical tool for nitrate determination in drinking and natural waters. ${ }^{4,32}$

\section{Flow injection measurements}

To speed up the analytical processes, the FIA is an attractive approach as it offers the versatility of operation, high sensitivity, low consumption of samples and reagents, and high analytical throughput compared to batch analysis. To evaluate the CuMEs performance in an FIA system, we used a platform with an array of 20 $\mathrm{Cu}$ microsensors and the "wall-jet" flow-cell described in "Flow cell design" sub-section for amperometric detection of glucose. Figure 6A shows the typical I-t curves obtained after injecting $100 \mu \mathrm{L}$ glucose standard solutions in quadruplicate at 25-600 $\mu \mathrm{mol} \mathrm{\textrm {L } ^ { - 1 }}$ range concentration in $0.10 \mathrm{~mol} \mathrm{~L}^{-1} \mathrm{NaOH}$ used as supporting electrolyte and carrier solution. The amperometric signals exhibited a low background current and excellent reproducibility on the anodic peak current signals for increasing glucose concentration.


analytical frequency of 80 determinations per hour. By using information from the calibration plot in the inset, which followed the equation $\mathrm{I}(\mathrm{nA})=1.42+0.323 \times \mathrm{C}_{\text {glucose }}$,

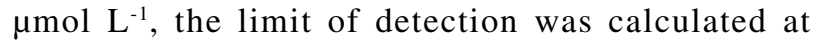
$1.7 \mu \mathrm{mol} \mathrm{L}^{-1}\left(3 \sigma_{\text {brank }}\right)$. The sensitivity of the $20 \mathrm{CuMEs}$ array was estimated at $734.1 \mu \mathrm{A} \mathrm{mmol}{ }^{-1} \mathrm{~L} \mathrm{~cm}^{-2}$ by dividing the

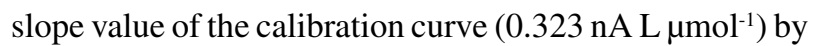
the geometric area of the array $\left(4.40 \times 10^{-4} \mathrm{~cm}^{2}\right)$. This value is favorable compared to some non-enzymatic methods for glucose sensing reported in the literature, ${ }^{33-39}$ and it can be attributed to the highly favorable faradaic-to-capacitive current ratio in the microelectrodes. The high sensitivity confirmed the excellent CuMEs arrays performance for glucose monitoring in low concentrations, like those found in some biological fluids such as salivary and sweat

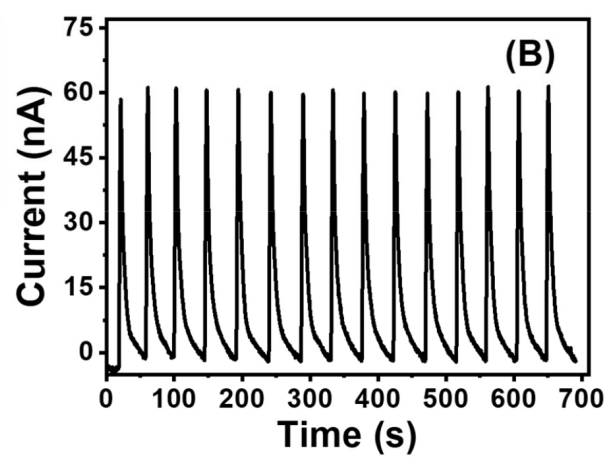

Figure 6. FIA-amperometric signals for increasing glucose concentration on an array of twenty CuMEs in $0.10 \mathrm{~mol} \mathrm{~L}^{-1} \mathrm{NaOH}_{\mathrm{Carrier}}$ solution at $1.0 \mathrm{~mL}$ min ${ }^{-1}$ flow rate. Glucose concentration: (a) 25; (b) 50; (c) 100; (d) 200; (e) 400; (f) $600 \mu \mathrm{mol} \mathrm{L}^{-1}$ (A). The inset corresponds to the resulting calibration curve. Repeatability of current signals measured after successive injections of $180 \mu \mathrm{mol} \mathrm{L}^{-1}$ glucose standard solution (B). Working electrode potential: $+0.55 \mathrm{~V} v s$. $\mathrm{Ag} / \mathrm{AgCl}$. 
samples. The typical linear concentration range of the method extended from $20 \mu \mathrm{mol} \mathrm{L}^{-1}$ to $4.0 \mathrm{mmol} \mathrm{L}^{-1}$. The glucose reproducibility measurements were evaluated by fifteen $180 \mu \mathrm{mol} \mathrm{L}^{-1}$ glucose solution successive injections in the flow system operating under $1.0 \mathrm{~mL} \mathrm{~min}^{-1}$ flow-rate (Figure 6B). The results indicated a $58.6 \mathrm{nA}$ mean anodic current value and a relative standard deviation (RSD) of $1.70 \%$. The excellent performance demonstrated with the CuMEs array in an FIA system opens new possibilities for sensing applications, including its coupling in electrochemical cells for batch injection analysis (BIA) and liquid-chromatography systems.

\section{Conclusions}

Arrays of CuMEs based on microchips have been successfully fabricated. The manufacturing process of copper microelectrodes is simple, cheap, and environmentalfriendly. Furthermore, it does not demand either special tools or a highly skilled operator. EDS and cyclic voltammetry were used to investigate the composition of the microelectrodes and the electrochemical behavior in $100 \mathrm{mmol} \mathrm{L}^{-1} \mathrm{NaOH}$ solution. The CuMEs platforms displayed excellent performance towards the glucose, hydrazine, and nitrate detection in batch and flow cells. By flow injection analysis, the proposed $\mathrm{Cu}$ microsensors arrays can detect glucose at a wide dynamic range with high sensitivity $\left(734.1 \mu \mathrm{A} \mathrm{mmol}^{-1} \mathrm{~L} \mathrm{~cm}^{-2}\right)$, demonstrating that they can be a good candidate for glucose monitoring in clinical diagnostics, biotechnology, food industry, and environmental fields.

\section{Supplementary Information}

Supplementary data are available free of charge at http://jbcs.sbq.org.br as a PDF file.

\section{Acknowledgments}

The authors are grateful to FAPESP (No. 2012/502598) for financial support. We also thank MackPesquisa and CNPq for the student grants provided to G.S.H. and G.F.S.

\section{References}

1. Martynov, L. Y.; Naumova, O. A.; Zaytsev, N. K.; Lovchinovsky, I. Y.; Tonkie Khim. Tekhnol. 2016, 11, 26.

2. Pei, X.; Kang, W.; Yue, W.; Bange, A.; Heineman, W. R.; Papautsky, I.; Anal. Chem. 2014, 86, 4893.

3. Li, Y.; Li, H.; Song, Y.; Lu, H.; Tong, J.; Bian, C.; Sun, J.; Xia, S.; IEEE Sens. J. 2016, 16, 8807.
4. Paixão, T. R. L. C.; Cardoso, J. L.; Bertotti, M.; Talanta 2007, $71,186$.

5. Barman, K.; Changmai, B.; Jasimuddin, S.; Electroanalysis 2017, 29, 2780.

6. Terzi, F.; Zanfrognini, B.; Dossi, N.; Ruggeri, S.; Maccaferri, G.; Electrochim. Acta 2016, 188, 327.

7. Thi Kim, L. T. O.; Escriou, V.; Griveau, S.; Girard, A.; Griscom, L.; Razan, F.; Bedioui, F.; Electrochim. Acta 2014, 140, 33.

8. Lin, Y. T.; Chen, C. H.; Lin, M. S.; Sens. Actuators, B 2018, $255,2838$.

9. Veloso, W. B.; Ribeiro, G. A. C.; da Rocha, C. Q.; Tanaka, A. A.; da Silva, I. S.; Dantas, L. M. F.; Measurement 2020, 155, 107516.

10. Shukla, R. P.; Belmaker, R. H.; Bersudsky, Y.; Ben-Yoav, H.; J. Neural Transm. 2020, 127, 291.

11. Wang, Z.; Deng, H.; Chen, L.; Xiao, Y.; Zhao, F.; Bioresour. Technol. 2013, 132, 387.

12. Rivera, J. F.; Sridharan, S. V.; Nolan, J. K.; Miloro, S. A.; Alam, M. A.; Rickus, J. L.; Janes, D. B.; Analyst 2018, 143, 4954.

13. Santos, C. S.; Bannitz-Fernandes, R.; Lima, A. S.; Tairum, C. A.; Malavazi, I.; Netto, L. E. S.; Bertotti, M.; Anal. Chem. 2018, 90, 2587.

14. Gunderson, C.; Zhang, B.; J. Electroanal. Chem. 2016, 781, 174.

15. Hay, C. E.; Lee, J.; Silvester, D. S.; Nanomaterials 2019, 9, 1170.

16. da Silva, I. S.; de Araujo, W. R.; Paixão, T. R. L. C.; Angnes, L.; Sens. Actuators, B 2013, 188, 94.

17. Pacheco, B. D.; Valério, J.; Angnes, L.; Pedrotti, J. J.; Anal. Chim. Acta 2011, 696, 53.

18. Pedrotti, J. J.; Angnes, L. L.; Gutz, I. G. R.; Electroanalysis 1996, $8,673$.

19. Orozco, J.; Fernández-Sánchez, C.; Jiménez-Jorquera, C.; Sensors 2010, 10, 475.

20. Luo, P.; Prabhu, S. V.; Baldwin, R. P.; Anal. Chem. 1990, 752.

21. Dong, S.; Xie, Y.; Cheng, G.; Electrochim. Acta 1992, 37, 17.

22. He, J. B.; Lu, D. Y.; Jin, G. P.; Appl. Surf. Sci. 2006, 253, 689.

23. Jiang, L. C.; Zhang, W.-D.; Biosens. Bioelectron. 2010, 25, 1402.

24. Farrell, S. T.; Breslin, C. B.; Electrochim. Acta 2004, 49, 4497.

25. Luo, L.; Zhu, L.; Wang, Z.; Bioelectrochemistry 2012, 88, 156.

26. Ensafi, A. A.; Abarghoui, M. M.; Rezaei, B.; Electrochim. Acta 2014, 123, 219.

27. Salazar, P.; Rico, V.; González-Elipe, A. R.; Electroanalysis 2018, 30, 187.

28. Zhang, J.; Zhu, X.; Dong, H.; Zhang, X.; Wang, W.; Chen, Z.; Electrochim. Acta 2013, 105, 433.

29. Xu, Q.; Zhao, Y.; Xu, J. Z.; Zhu, J. J.; Sens. Actuators, B 2006, 114, 379.

30. Salazar, P.; Rico, V.; Rodríguez-Amaro, R.; Espinós, J. P.; González-Elipe, A. R.; Electrochim. Acta 2015, 169, 195. 
31. Pletcher, D.; Poorabedi, Z.; Electrochim. Acta 1979, 24, 1253.

32. Leal, T. F. M.; Fontenele, A. P. G.; Pedrotti, J. J.; Fornaro, A.; Quim. Nova 2004, 27, 855.

33. Reitz, E.; Jia, W.; Gentile, M.; Wang, Y.; Lei, Y.; Electroanalysis 2008, 20, 2482.

34. Tang, Y.; Liu, Q.; Jiang, Z.; Yang, X.; Wei, M.; Zhang, M.; Sens. Actuators, B 2017, 251, 1096.

35. Yang, J.; Tan, W.; Chen, C.; Tao, Y.; Qin, Y.; Kong, Y.; Mater. Sci. Eng., C 2017, 78, 210.

36. Figiela, M.; Wysokowski, M.; Galinski, M.; Jesionowski, T.; Stepniak, I.; Sens. Actuators, B 2018, 272, 296.
37. Song, J.; Xu, L.; Zhou, C.; Xing, R.; Dai, Q.; Liu, D.; Song, H.; ACS Appl. Mater. Interfaces 2013, 5, 12928.

38. Jang, K. B.; Park, K. R.; Kim, K. M.; Hyun, S. K.; Jeon, J. E.; Song, Y. S.; Park, S. K.; Moon, K.-i.; Ahn, C.; Lim, S. C.; Lee, J.; Kim, J. C.; Han, H.; Mhin, S.; Nanomaterials 2021, 11, 55.

39. Martins, P. R.; Rocha, M. A.; Angnes, L.; Toma, H. E.; Araki, K.; Electroanalysis 2011, 23, 2541.

Submitted: May 14, 2021 Published online: August 6, 2021 